\title{
As influências na motivação para o trabalho em ambientes com metas e recompensas: um estudo no setor público
}

\author{
Weslei Alves Rodrigues \\ Universidade Fumec \\ Mário Teixeira Reis Neto \\ Universidade Fumec
}

Cid Gonçalves Filho

Universidade Fumec

\begin{abstract}
Este estudo investigou as influências na motivação para o trabalho apoiando-se nas teorias de Latham e Locke (2002), Porter e Lawler III (1968), Vroom (1964) e Wright (2001, 2007). Foi realizado um survey com 333 funcionários públicos de seis órgãos estaduais e um municipal na cidade de Belo Horizonte (MG), que possuíam políticas de metas e recompensas. A motivação dos funcionários se mostrou influenciada de forma direta e significativa pela valência da missão institucional, pela instrumentalidade ligada às recompensas e pela autoeficácia no alcance das metas. A especificidade e o feedback em relação às metas influenciaram a motivação de forma significativa e indireta. A importância das metas, a valência das recompensas extrínsecas, a expectativa, a equidade, a participação na definição das metas, a dificuldade das metas, a avaliação geral dos sistemas de metas e a avaliação geral dos sistemas de recompensas não exerceram influências diretas na motivação. Os funcionários de faixa etária mais elevada apresentaram maiores médias de motivação. Já os funcionários ocupantes de cargo de chefia e os que recebiam algum tipo de recompensa extra (além do salário fixo) apresentaram índices mais elevados em fatores relacionados à motivação.
\end{abstract}

Palavras-chave: metas; motivação; remuneração variável; administração pública.

Las influencias en la motivación para el trabajo en ambientes con metas y recompensas: un estudio en el sector público

Este estudio investigó las influencias en la motivación para el trabajo apoyándose en las teorías de Latham y Locke (2002), Porter y Lawler III (1968), Vroom (1964) y Wright (2001, 2007). Se realizó una encuesta con 333 funcionarios públicos de 6 agencias del estado y 1 municipal en la ciudad de Belo Horizonte, Minas Gerais, Brasil, que tenían políticas de metas y recompensas. La motivación de los funcionarios se mostró directa y significativamente influenciada por la valencia de la misión ins-

Artigo recebido em 14 nov. 2011 e aceito em 4 out. 2013. 
titucional, por la instrumentalidad ligada a las recompensas y por la auto-eficacia en el logro de las metas. La especificidad y el feedback con relación a las metas influenciaron la motivación de manera indirecta y significativa. La importancia de las metas, la valencia de las recompensas extrínsecas, la expectativa, la equidad, la participación en la definición de las metas, la dificultad de las metas, la evaluación general de los sistemas de metas y la evaluación general de los sistemas de recompensas no ejercieron influencias directas en la motivación. Los funcionarios de franja etaria más alta presentaron mayores medias de motivación. Ya los funcionarios que ocupan puestos de liderazgo y los que recibían algún tipo de recompensa extra (además del salario fijo) presentaron índices más altos en factores relacionados con la motivación.

Palabras clave: metas; motivación; remuneración variable; administración pública.

Influences on work motivation in environments with goals and rewards: a study in the public sector

This study investigated influences on work motivation based on the theories of Latham and Locke (2002), Porter and Lawler III (1968), Vroom (1964), and Wright (2001, 2007). We conducted a survey with 333 public officials from 6 state agencies and 1 municipal agency in the city of Belo Horizonte, Minas Gerais, Brazil, which had policies for goals and rewards. Officials' motivation showed to be directly and significantly influenced by the valence of the institutional mission, through the instrumentality related to rewards and self-effectiveness to achieve goals. The specificity and feedback with regard to goals influenced the motivation in a significant and indirect way. The importance of goals, valence of extrinsic rewards, expectation, equity, participation in the setting of goals, difficulty of goals, overall evaluation of goal systems, and overall evaluation of reward systems did not exert direct influences on motivation. Officials' from an older age group had higher average values for motivation. In turn, officials occupying leadership positions and those who received some kind of extra reward (in addition to wage) showed higher indices in factors related to motivation.

KEYwords: goals; motivation; variable remuneration; public administration.

\section{Introdução}

O movimento de reforma e modernização da gestão no setor público brasileiro nas duas últimas décadas tem se pautado na lógica da administração pública gerencial (Bresser-Pereira e Spink, 2006:28). Segundo Souza (2005:1), esse modo de administrar contempla a adoção de ferramentas de gestão provenientes de empresas privadas, como a definição de metas e a concessão de recompensas extras aos funcionários. É o que já ocorre em boa parte dos órgãos públicos estaduais mineiros. O governo de Minas Gerais adotou um sistema no qual são pactuadas metas de desempenho entre os dirigentes de órgãos e entidades do Poder Executivo que, caso sejam alcançadas, podem garantir premiações em dinheiro aos servidores (Vilhena et al., 2006). Além da possibilidade de garantir maior eficiência e eficácia nas ações governamentais, a gestão com metas e recompensas pode possibilitar o alcance de maiores níveis de motivação para o trabalho, por parte dos funcionários (Locke e Latham, 2002; Porter e Lawler, 1968; Vroom, 1964; Wright, 2001, 2007). 
Apesar da ampla utilização na iniciativa privada, o uso de metas e recompensas na administração pública é relativamente recente. Talvez em decorrência disso, tais ferramentas são ainda pouco exploradas na pesquisa e na literatura de gestão pública. Também não consta a existência da influência das metas e das recompensas na motivação dos funcionários públicos do Brasil. Considerando a existência de tal lacuna, optou-se por realizar o presente estudo, orientado pela seguinte questão: como a motivação para o trabalho é afetada em ambientes com metas e recompensas? Dessa forma, o objetivo geral da pesquisa foi identificar como as características das metas e recompensas praticadas influenciam a motivação dos funcionários públicos no trabalho. Para alcançar tal objetivo, foram estabelecidos os seguintes objetivos específicos: identificar como os funcionários públicos avaliam as metas e as recompensas nas instituições onde trabalham; identificar os níveis de motivação para o trabalho dos funcionários públicos; estudar as relações existentes entre as metas, as recompensas e essa motivação; estudar como as características individuais se relacionam com as metas, as recompensas e a motivação.

\section{Revisão da literatura}

\subsection{A motivação para o trabalho}

Uma corrente teórica que muito influenciou os estudos sobre a motivação no trabalho se apoia no conceito da motivação intrínseca. Dentro dela, Sawrey e Telford (1976:18) definiram a motivação como "uma condição interna relativamente duradoura que leva o indivíduo, ou que o predispõe, a persistir num comportamento orientado para um objetivo, possibilitando a transformação ou a permanência de situação". Para Frohman (1996:13), a motivação pode ser definida em termos de algum comportamento externo. As pessoas que estão motivadas exercem um esforço maior para desempenhar uma tarefa do que as pessoas que não o estão. Vroom (1964:15), ao dar uma definição mais descritiva, afirmou "que a motivação seria a disposição de fazer alguma coisa, quando esta coisa é condicionada por sua capacidade de satisfazer alguma necessidade do indivíduo". Consequentemente, a motivação é vista como uma força propulsora, cujas origens se encontram na maior parte do tempo escondidas no interior do indivíduo. É a motivação intrínseca e se aplica às pessoas de uma maneira geral, tanto para ações no trabalho quanto fora dele.

Para Lawler III (2000:79), que ampliou o trabalho de Vroom, a motivação no trabalho foi também definida por Schermerhorn e colaboradores: "é função da importância da recompensa e do grau que as recompensas estão vinculadas a um desempenho ou comportamento específico". A motivação no trabalho foi também definida por Schermerhorn Jr., Hunt e Osborn (1999:86) como "as forças dentro de uma pessoa responsáveis pelo nível, direção e persistência de esforço despendido no trabalho". Nesta definição, o nível é a quantidade de esforço que a pessoa emprega, isto é, quão duro trabalha (por exemplo: muito ou pouco); a direção é o que a pessoa opta por fazer quando está em face de um grande número de alternativas possíveis 
(por exemplo: se vai empregar o esforço visando à qualidade ou à quantidade do produto); a persistência se refere a quanto tempo a pessoa continua numa determinada ação (por exemplo: desiste se está difícil, ou continua tentando).

Sintetizando Ryan (2012), pode-se dizer que, às vezes, a motivação das pessoas é explícita na consciência. Às vezes, o comportamento é claramente energizado e dirigido pela não consciência, por objetivos implícitos e pelas atitudes. Finalmente, sejam os motivos implícitos ou explícitos, o comportamento organizado por eles serão as variáveis do sucesso. Motivação eficaz requer não só a excitação ou energia, mas também um sistema de orientação afetiva e cognitiva que, pelo menos para a maioria das pessoas, é suscetível a distrações ou esgotamento. Segundo Manolopoulos (2008), as diferenças individuais e as características do trabalho de contexto podem levar a diferenças na motivação dos funcionários, satisfação no trabalho e desempenho.

Lashey e Lee-Ross (2003) classificam as teorias da motivação em dois grupos segundo o foco. Para eles, o primeiro grupo foca a satisfação das necessidades dos indivíduos. O segundo foca o processo cognitivo envolvido a partir da criação de prioridades em função das necessidades motivacionais de cada um: são as teorias cognitivas. Para Freitas (2006:23), "o grupo das teorias das necessidades (...) destaca as necessidades internas das pessoas e o comportamento resultante do esforço por elas realizado para reduzir ou saciar essas necessidades". A autora relaciona as seguintes teorias como parte desse grupo: a Teoria das Necessidades de Maslow; a Teoria das Necessidades de Frederick Herzberg; a teoria das necessidades de Alderfer (ERG) e a teoria das necessidades de McClelland. Com relação às teorias cognitivas, a autora acredita que "(...) focalizam-se na compreensão do processo subjacente à motivação para o trabalho, tentando explicá-la através do enfoque numa insuficiência ao nível das necessidades e no comportamento resultante dessa situação". As teorias que se enquadram nesse grupo são: a teoria da equidade, a teoria do reforço, a teoria da definição de metas e a teoria das expectativas. A questão proposta para o presente estudo encontra embasamento nas teorias classificadas acima como cognitivas, com destaque para a teoria das expectativas e a teoria da definição de metas.

\subsection{A motivação no setor público}

Algumas características peculiares das instituições do setor público influenciam a motivação e o comportamento dos funcionários de forma distinta dos padrões observados nas empresas privadas. Para Houston (2000), as pessoas ocupadas no setor público têm valores e motivos diferentes daquelas empregadas em organizações privadas. Crewson (1997) reforça que, além de motivações, os funcionários públicos têm expectativas diferentes em comparação aos empregados de empresas privadas. Ele ressalta que o estudo do comportamento humano nas organizações deve contemplar a investigação das relações entre os contextos organizacionais, sistemas de recompensa, motivação dos funcionários e padrões de resultados.

A nobreza da missão do serviço público é percebida, por muitos autores, como o mais potente fator de motivação dos funcionários para o trabalho. Para Mann (2006), o motivo 
para servir o bem público é prevalecente na força de trabalho das instituições públicas e essa diferença deve ser aproveitada como força motivadora pelos gestores. Chanlat (2002:7) reforça esse entendimento ao afirmar que "o orgulho de pertencer a uma categoria que se define pelo serviço dos outros é um poderoso fator de motivação, quando realmente assim vivido". O autor acredita que a reflexão sobre a motivação para o trabalho no setor público passa, obrigatoriamente, pela importância e pelo papel que representa a ética do bem comum, inerente ao tipo de trabalho desenvolvido.

\subsection{Os efeitos das metas sobre a motivação para o trabalho}

A definição de um sistema de metas na organização é uma ferramenta de gestão que pode apresentar efeito significativo sobre a motivação e o desempenho dos empregados. Para Reis Neto e Marques (2003:7), "as metas dizem a um empregado o que precisa ser feito e quanto esforço será necessário empregar”. Quando o funcionário tem clareza daquilo que precisa buscar, torna-se mais fácil canalizar energias para alcançar o resultado. Para Latham e Locke (1979), a definição de metas, além de ser mais efetiva do que outros métodos, pode representar o principal mecanismo pelo qual esses outros incentivos afetam a motivação.

A figura 1 apresenta o modelo teórico que destaca os elementos essenciais da teoria da definição de metas, de Locke e Latham (2002).

$$
\text { Figura } 1
$$

Elementos essenciais da teoria da definição de metas e o ciclo do alto desempenho de Locke e Latham (2002)

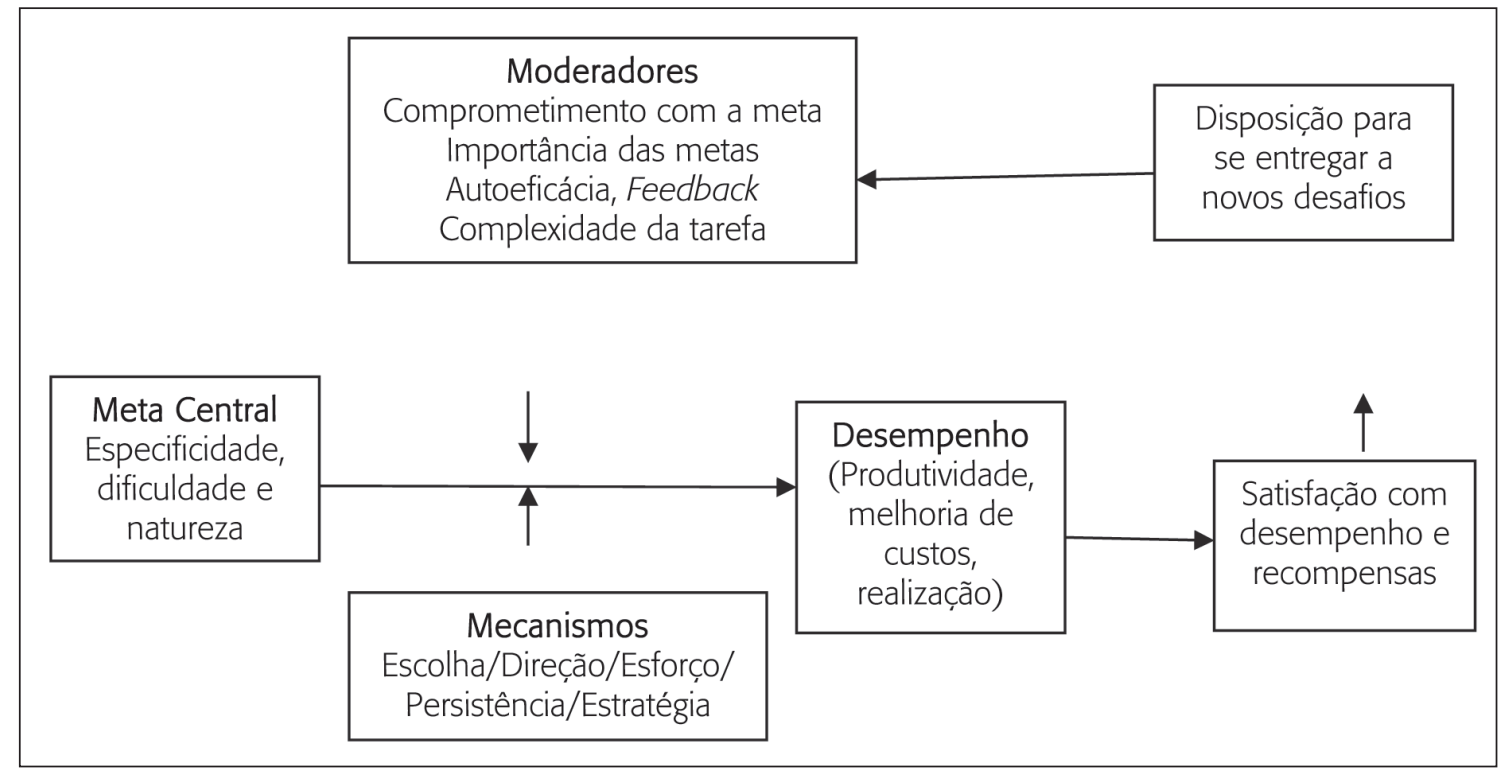

Fonte: Locke e Latham (2002; adaptação). 
No modelo, os autores destacam que o desempenho é afetado diretamente por três grupos de fatores. O primeiro grupo é composto pelos fatores que atuam como moderadores. São eles: o comprometimento do empregado com a meta, a importância que os funcionários atribuem às metas, o feedback recebido pelo empregado sobre seu desempenho com as metas, o nível de complexidade da tarefa e a autoeficácia, ou seja, a crença do empregado na própria capacidade para a realização do trabalho e o alcance das metas. O segundo grupo contempla as questões centrais das metas, como a especificidade, a dificuldade e a natureza. A natureza das metas diz respeito a elas serem de desempenho, de aprendizado ou proximais (de curto prazo). O terceiro grupo é composto por outros mecanismos, como escolha da tarefa, direção, esforço do empregado na execução, persistência e estratégia utilizada. O modelo mostra, ainda, que o desempenho e as recompensas podem gerar satisfação nos funcionários. A satisfação afeta a disposição dos funcionários a se entregarem a novos desafios. Esse processo proporciona um link de retroalimentação nos moderadores citados, conforme indicado no modelo teórico.

\subsection{Os efeitos das metas sobre a motivação no setor público}

Wright (2001) pesquisou a validade das teorias das metas e das teorias cognitivas sociais no setor público. O autor avaliou a influência de quatro antecedentes da motivação para o trabalho, que foram previamente identificados nessas teorias: a especificidade, a dificuldade, a importância das metas e a autoeficácia. Com base, sobretudo, nas teorias da administração pública, foram também incorporados ao estudo outros construtos para análise da influência sobre a motivação: as metas conflitantes, os constrangimentos processuais, a estrutura de recompensas e o feedback. Os resultados confirmaram a validade das teorias da definição de metas e das teorias cognitivas sociais no setor público. Foi identificada a influência direta sobre a motivação para o trabalho no setor público por parte de três das quatro variáveis testadas: dificuldade das metas, autoeficácia e especificidade das metas. Quase três quartos da variância total da motivação dos funcionários públicos no trabalho foram explicados por essas três variáveis. O estudo confirmou o papel que desempenham as variáveis de contexto no modelo da motivação para o trabalho e confirmou que as diferenças (peculiaridades) do setor podem ter um importante efeito sobre a motivação dos funcionários.

Em outro estudo realizado por Wrigth (2007), verificou-se que os funcionários públicos são mais motivados para o trabalho quando têm tarefas desafiadoras, claramente entendidas e que eles acreditam ser importantes e alcançáveis (figura 2). Outra influência vem da valência da missão, ou seja, o valor intrínseco que os funcionários percebem na missão institucional. Isso ocorre porque a missão incrementa a importância da tarefa a ser realizada. A disponibilidade de recompensas extrínsecas relacionadas ao desempenho tem uma influência significativa no grau de importância que os funcionários atribuem a seus trabalhos. No entan- 
to, essa influência foi menor do que aquela atribuída às recompensas intrínsecas provenientes da missão institucional.

Como pode ser observado no modelo, o autor constatou que a importância do trabalho afeta diretamente a motivação e confirmou seus estudos de 2001, que apontaram a influência da dificuldade do trabalho, da autoeficácia e da especificidade do trabalho na motivação.

Figura 2

Modelo de motivação no trabalho no setor público de Wright (2007)

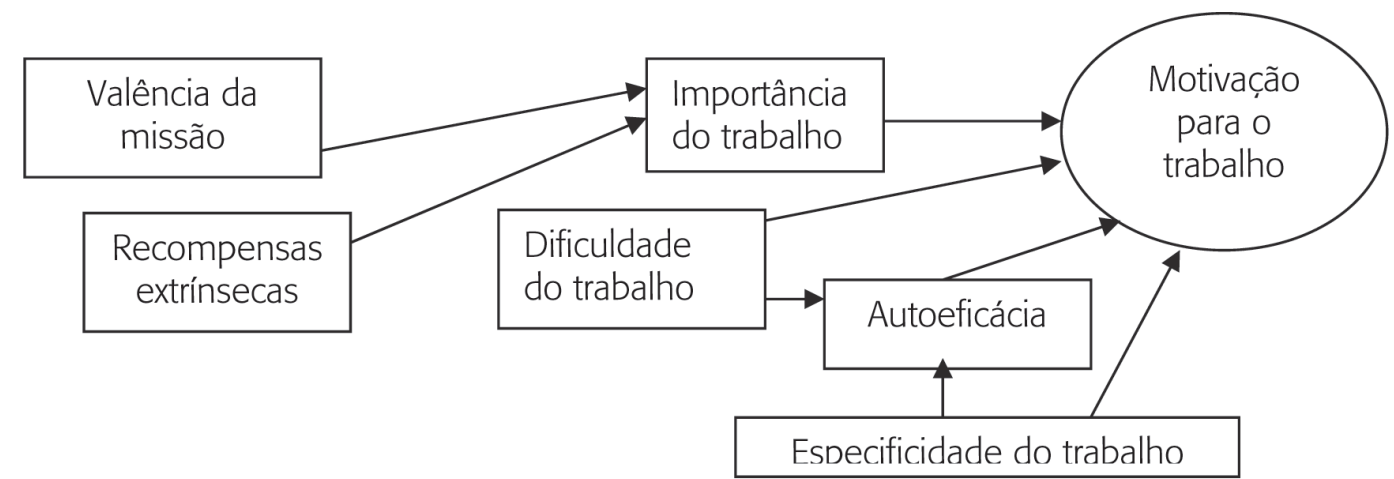

Fonte: Wright (2007; adaptação).

\subsection{Os efeitos das recompensas sobre a motivação para o trabalho}

Uma das principais teorias que relacionam as recompensas com a motivação é a teoria da expectativa, elaborada por Vroom (1964). Ela explica que a motivação de uma pessoa depende do produto entre a expectativa, a instrumentalidade e a valência. Nela, a expectativa é a percepção de que o esforço empregado em uma tarefa conduzirá ao desempenho desejado. A instrumentalidade é a percepção de que o desempenho conduzirá a uma recompensa e a valência é o valor que a pessoa atribui à recompensa recebida. A partir da teoria da expectativa, Porter e Lawler III (1968) propuseram o modelo teórico mostrado na figura 3 com o intuito de relacionar esforço, desempenho, satisfação e outras variáveis importantes. Nesse modelo, os autores sugerem que o nível de esforço empregado na tarefa é influenciado diretamente pelo valor da recompensa e pela probabilidade percebida de recompensa pelo esforço. O esforço empregado pode ou não resultar no desempenho desejado para a empresa. O modelo sugere que o esforço tem maior probabilidade de resultar no desempenho desejado quando o empregado possui habilidades e competências compatíveis com a tarefa e quando há de sua parte uma clara percepção dos papéis, ou seja, quando ele sabe o que deve ser feito para alcançar o desempenho desejado. Na sequência, o modelo indica que o desempenho pode resultar em 
dois tipos de recompensas: as intrínsecas e as extrínsecas. As recompensas intrínsecas, segundo os autores, são aquelas administradas pelo próprio indivíduo e as recompensas extrínsecas são aquelas administradas pela organização.

O modelo teórico da figura 3 mostra que as recompensas recebidas e a percepção de equidade gerada pelas recompensas contribuirão para definir os níveis de satisfação do empregado. Esses níveis influenciam a percepção de valor da recompensa e funcionam como um laço de feedback no processo. Simultaneamente, a percepção de equidade das recompensas é decorrente do julgamento de compatibilidade entre seu desempenho e as recompensas recebidas. Outro laço de feedback estabelece a relação entre o desempenho, as recompensas e a probabilidade percebida de recompensa pelo esforço. O modelo mostra que o desempenho alcançado pelo empregado, juntamente com as recompensas recebidas, influenciará a sua percepção de que o esforço resulta em recompensa.

Figura 3

Relação entre recompensa, esforço e desempenho individual, de Porter e Lawler III (1968)

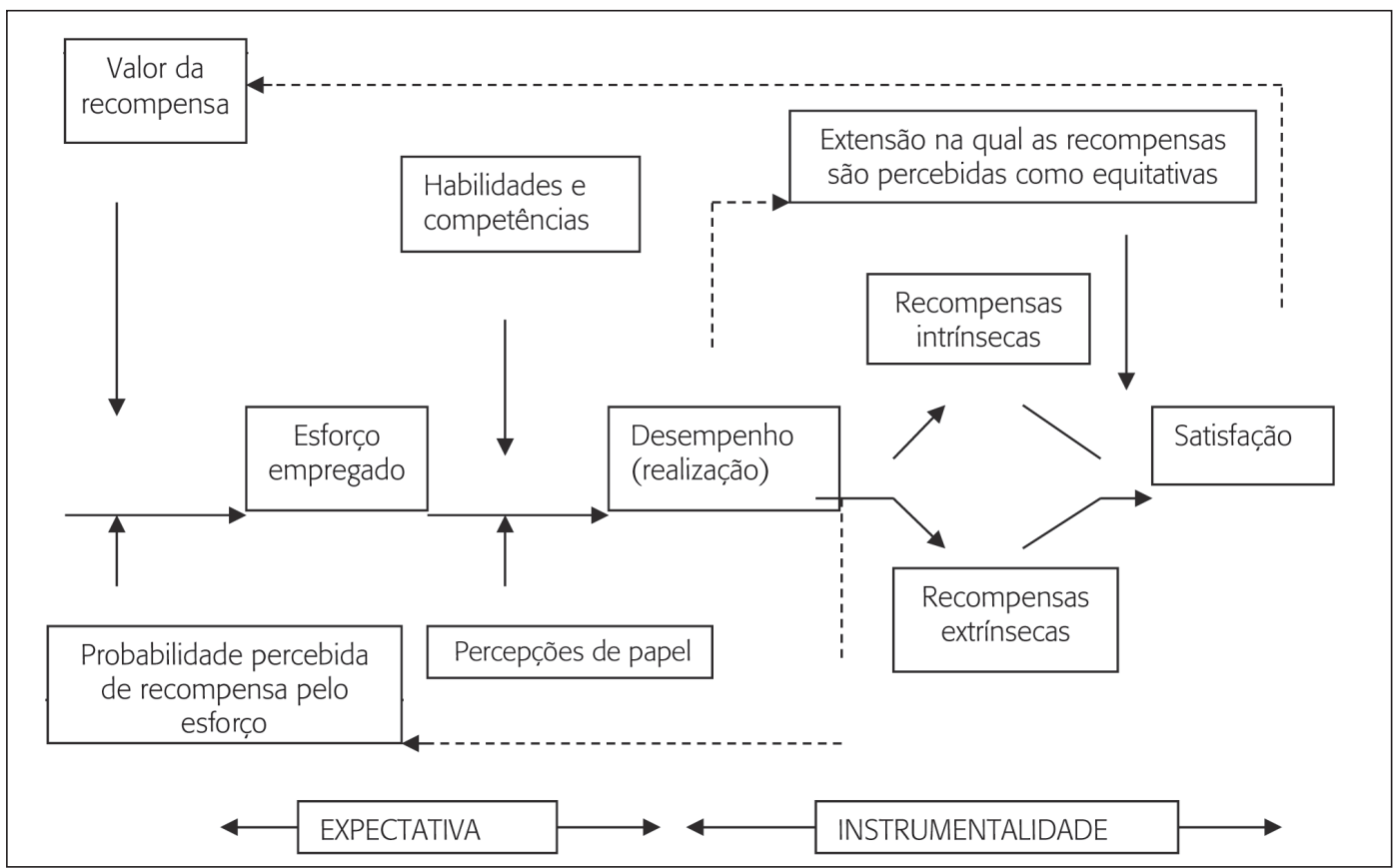

Fonte: Porter e Lawler III (1968; adaptação).

Alguns autores recomendam cautela e apresentam contrapontos ao uso de recompensas na gestão de pessoas. De acordo com Deci e Ryan (2000), na teoria da avaliação cognitiva, a introdução de recompensas externas para trabalhos anteriormente gratificantes apenas pelo seu conteúdo tende a reduzir a motivação. Cameron, Banko e Pierce (2001) 
salientam, no entanto, que isso ocorre apenas nas atividades que são consideradas, naturalmente, mais interessantes pelos funcionários e somente quando as recompensas são tangíveis, esperadas e sem ligação com os níveis de desempenho. No caso das atividades caracterizadas por pouco ou nenhum interesse em sua execução, as recompensas externas podem ser motivadoras. Os autores acrescentam ainda que, quando as recompensas são vinculadas aos níveis de desempenho alcançados pelos funcionários, a motivação intrínseca pode ser até aumentada.

\subsection{Os efeitos das recompensas sobre a motivação no setor público}

Crewson (1997) sugere a necessidade de equilíbrio e adequação na concessão de recompensas econômicas para não destruir ou ignorar as necessidades intrínsecas do trabalho dos funcionários no setor público. Ele acredita que o esclarecimento de missões, objetivos, metas e o reconhecimento do potencial próprio de motivação de um serviço público devem ser priorizados sobre a convicção de que as recompensas monetárias são a chave para o aumento da produtividade e melhoria do serviço. Para Buelens e Broeck (2007), trabalhadores do setor público são menos motivados pelos fatores extrínsecos em comparação com funcionários do setor privado. Houston (2000) acredita que o funcionário público está propenso a atribuir mais valor às recompensas intrínsecas do trabalho porque esse setor tem atividades importantes e proporciona o sentimento de realização.

Para Wright (2007), as recompensas extrínsecas afetam a importância atribuída ao trabalho e essa importância afeta diretamente a motivação dos funcionários públicos para a realização de suas tarefas. De qualquer maneira, o autor não diverge das afirmações anteriores. Ele admite que as recompensas extrínsecas afetam a importância do trabalho em menor intensidade do que as recompensas intrínsecas atribuídas à missão institucional do serviço público.

\section{Metodologia de pesquisa}

Foi realizada uma pesquisa de natureza descritiva (Gil, 2002) utilizando-se um survey de corte transversal com variáveis quantitativas, conforme descrito por Malhotra (2001) e Vieira (2002).

\section{0 modelo estudado}

As influências sobre a motivação para o trabalho em ambientes com metas e recompensas foram com base no modelo apresentado na figura 4, elaborado a partir das principais teorias revisadas (Locke e Latham, 2002; Porter e Lawler III, 1968; Vroom, 1964; Wright, 2001, 2007). O modelo estabelece uma relação direta da percepção de cada construto relacionado 
às metas e recompensas com a motivação para o trabalho. As ligações constantes no modelo (setas) representam o pressuposto de que existe relação significativa e direta entre a variável independente e a variável dependente.

Figura 4

\section{Modelo analítico de relações entre variáveis}

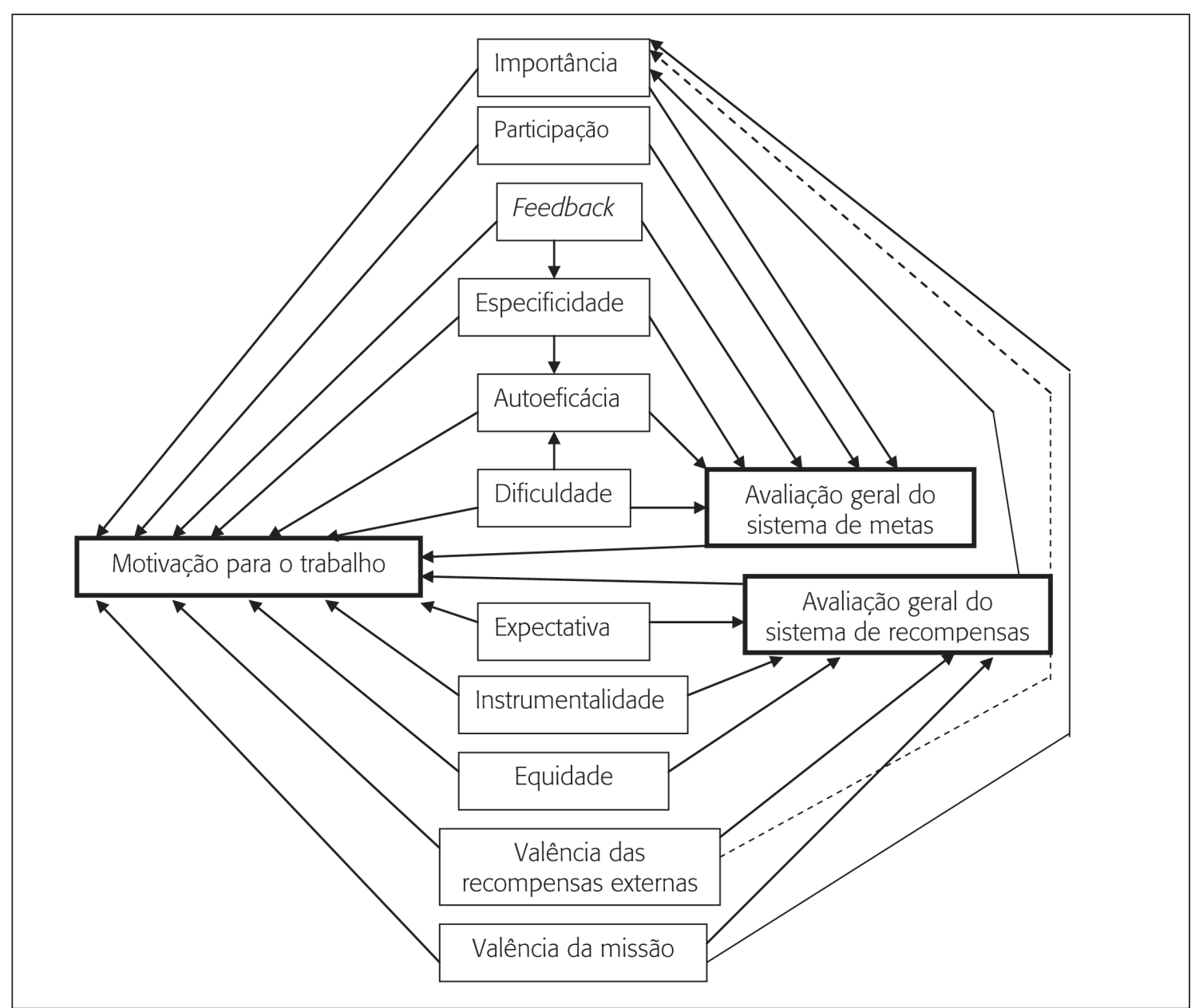

Fonte: Elaborado pelos autores a partir da base teórica estudada.

\section{Métodos e técnicas}

O modelo proposto foi testado empregando o método de modelagem de equações estruturais (Maruyama, 1998). Para se estimar o modelo de pesquisa, empregou-se o método contemporâneo de estimação por Mínimos Quadrados Parciais (Partial Least Squares — PLS), devido à 
ausência do pressuposto de normalidade e seu melhor desempenho relativo perante amostras de tamanho moderado e modelos relativamente complexos (Haenlein e Kaplan, 2004). Utilizou-se o método Chaid para estudar as relações entre as características individuais, as metas, as recompensas e a motivação. Foram utilizados os softwares Microsoft Excel 4.0, Smartpls 2.0 e SPSS 15.0 .

\section{o instrumento de coleta de dados, a amostra e o trabalho de campo}

A coleta dos dados foi realizada por meio de questionário não identificado e estruturado com questões fechadas. Os entrevistados avaliaram afirmativas que objetivaram a medição dos construtos especificidade, dificuldade e importância das metas, participação na definição das metas, feedback sobre o alcance das metas, autoeficácia, avaliação geral do sistema de metas, expectativa, instrumentalidade, equidade, valência das recompensas externas, valência da missão, avaliação geral dos sistemas de recompensas e motivação para o trabalho. As respostas foram informadas tendo como referência uma escala do tipo intervalar de 11 pontos, com a nota 0 (zero) correspondendo a "discordo totalmente" e a nota 10 (dez) correspondendo a "concordo totalmente". Foram apuradas as seguintes variáveis demográficas: tipo de remuneração (fixa ou variável), idade, sexo, estado civil, faixa salarial, nível de escolaridade, tipo de vínculo com a instituição, tempo de casa e nível hierárquico. Os questionários foram aplicados pessoalmente em visita aos órgãos selecionados.

A amostra utilizada foi composta voluntariamente por 333 funcionários públicos mineiros, lotados em seis órgãos estaduais e um órgão municipal na cidade de Belo Horizonte (MG), escolhidos por conveniência, sendo 239 funcionários do estado $(71,8 \%$ do total da amostra) e 94 do município (28,2\% do total da amostra). Com a exceção do órgão municipal, todos os selecionados fazem parte do acordo de resultados e possuem, portanto, políticas formais de definição de metas com previsão de recompensas.

\section{Apresentação e análise dos resultados}

O perfil da amostra apresentou predominância de funcionários acima de 31 anos (76\%), maioria do sexo feminino (55\%), casados (51\%), remuneração concentrada entre R\$1.000,00 e R\$ 2.500,00 (55\%), com formação superior ou pós-graduação (74\%), concursados (78\%), com tempo de casa superior a três anos (75\%) e sem cargo de chefia (74\%). Aproximadamente $48 \%$ da amostra admitiram receber algum tipo de recompensa extra, além do salário fixo ou comissão por cargo de confiança. Este resultado mostra que grande parte dos respondentes já havia sido afetada pelas recentes mudanças promovidas na gestão dos órgãos estaduais, nos quais foram definidas recompensas extras aos funcionários, vinculadas ao alcance de metas.

Os dados ausentes foram reduzidos a zero após a exclusão de alguns cargos destoantes na amostra, seguida da reposição dos dados restantes pelo procedimento de regressão. Foi 
admitida a não normalidade uni e multivariada dos dados após as análises. Desta forma, foi constatada a necessidade de buscar, na análise dos dados, procedimentos robustos à violação desse pressuposto (Tabachinick e Fidell, 2001). Os outliers identificados foram considerados elementos válidos da população. Como não seria correto eliminá-los, optou-se pela diminuição de seus escores, de modo a reduzir sua influência na análise, tal como sugere Kline (1998). A análise de linearidade e de multicolinearidade mostrou evidências de um bom ajuste linear entre as variáveis. Na matriz de correlação identificaram-se 1.325 correlações significativas, que representaram $89 \%$ do total de correlações da matriz.

Usando o método sugerido por Gerbing e Anderson (1988), aplicou-se a análise fatorial exploratória (AFE) com extração por componentes principais para avaliar a unidimensionalidade dos construtos. Os resultados de todas as escalas mostraram o atendimento da unidimensionalidade, com excelente qualidade e sem necessidade de exclusão de variáveis. A variância explicada variou entre 64 e 89\%, demonstrando sempre resultados aceitáveis em termos de compartilhamento de variação. Também as medidas KMO de adequação da amostra revelam boas condições para aplicação da AFE.

Com o intuito de avaliar a confiabilidade e a validade das medidas, procedeu-se ao uso de técnicas de modelagem de equações estruturais (Mackenzie, 2001; Bagozzi, Yi e Philips, 1991; Fornell e Lacker, 1981). Aplicou-se a estimação por mínimos quadrados parciais (Partial Least Squares - PLS) devido à ausência do pressuposto de normalidade e seu melhor desempenho relativo perante amostras de tamanho moderado (Haenlein e Kaplan, 2004).

Com o uso do alfa de Cronbach e da confiabilidade composta verificou-se que os construtos ficaram acima dos patamares desejados, indicando elevada congruência entre os dados empíricos e os construtos desejados. Com isto, pode-se afirmar que os dados apresentam confiabilidade aceitável, dentro dos parâmetros estabelecidos na literatura (Hair Jr. et al., 1998; Malhotra, 2001; Netemeyer, Bearden e Sharma, 2003).

Em sequência, avaliou-se a validade convergente. Os resultados obtidos com o uso da técnica de modelagem de equações estruturais pelo PLS apontaram cargas (loadings) para as relações entre os construtos do estudo e seus indicadores com valores altos, a maioria superior a 0,800. Este patamar é superior ao sugerido por Hulland (1999) como indício de validade convergente. Quanto ao percentual de variância explicada de cada indicador $\left(\mathrm{R}^{2}\right)$, verificou-se elevada convergência dos indicadores aos pretendidos construtos. Em sequência, foi avaliada a validade discriminante (Nunnaly e Bernstein, 1994) utilizando o processo sugerido por Fornell e Larcker (1981). Os resultados obtidos apontaram que todos os construtos obtiveram validade discriminante, podendo-se afirmar que suas medidas refletem questões distintas.

Com o intuito de alcançar o objetivo de estudar como as características individuais se relacionam com as metas, as recompensas e a motivação, foi aplicado o método Chaid (Kass, 1980). As características demográficas foram definidas como as variáveis independentes e os construtos foram definidos como variáveis dependentes. Os resultados mostraram que a 
faixa etária, o tipo de recompensa e o nível hierárquico influenciaram de forma significativa os construtos relacionados a metas, recompensas e motivação. A faixa etária influenciou diretamente os construtos: autoeficácia, importância, motivação e valência da missão. Percebeu-se nos resultados que as pessoas com mais de 36 anos apresentaram níveis maiores de autoeficácia, de percepção de importância das metas, de motivação para o trabalho e de percepção de valência na missão institucional. O tipo de recompensa influenciou a equidade, a expectativa, a instrumentalidade, a avaliação do sistema de recompensas e a valência das recompensas externas. Em outras palavras, verificou-se que pessoas que recebem algum tipo de recompensa extra, além do salário fixo, apresentam maiores níveis de percepção de equidade e de instrumentalidade, avaliam melhor o sistema de recompensas e atribuem maior valor às recompensas externas. Finalmente, o nível hierárquico influenciou os seguintes construtos: dificuldade, especificidade, feedback, participação e avaliação do sistema de metas. Isso mostra que pessoas com algum nível de chefia consideram as metas mais difíceis, com maiores níveis de especificidade, percebem maiores níveis de feedback e participação na elaboração das metas e avaliam melhor o sistema de metas.

\subsection{Análise do modelo}

Os resultados do teste do modelo mostraram que a motivação teve 53,1\% de sua variância explicada pelas variáveis independentes. A tabela 1 mostra as relações entre variáveis testadas no modelo com seus respectivos pesos padronizados obtidos com os mínimos quadrados parciais (PLS). As relações significativas estão destacadas em negrito.

Tabela 1

Relações entre as variáveis do modelo

\begin{tabular}{cccccc|}
\hline INDEPENDENTES & DEPENDENTES & PESO & ERRO & T & SIG. \\
\hline Dificuldade & Autoeficácia & $-0,06$ & 0,04 & 0,64 & 0,26 \\
Especificidade & Autoeficácia & 0,52 & 0,07 & 7,78 & 0,00 \\
Feedback & Especificidade & 0,50 & 0,06 & 8,85 & 0,00 \\
Avaliação das recompensas & Importância & 0,26 & 0,09 & 2,86 & 0,00 \\
Valência das recompensas externas & Importância & $-0,19$ & 0,09 & 2,02 & 0,02 \\
Valência da missão & Importância & 0,54 & 0,06 & 8,58 & 0,00 \\
Autoeficácia & Motivação para trabalho & 0,20 & 0,08 & 2,39 & 0,01 \\
Dificuldade & Motivação para trabalho & $-0,07$ & 0,05 & 0,89 & 0,19 \\
Equidade & Motivação para trabalho & $-0,15$ & 0,10 & 1,45 & 0,07 \\
Especificidade & Motivação para trabalho & 0,09 & 0,06 & 0,92 & 0,18 \\
Expectativa & Motivação para trabalho & 0,07 & 0,05 & 0,13 & 0,45 \\
\hline
\end{tabular}




\begin{tabular}{cccccc}
\hline INDEPENDENTES & DEPENDENTES & PESO & ERRO & T & SIG. \\
\hline Feedback & Motivação para trabalho & 0,14 & 0,09 & 1,47 & 0,07 \\
Importância & Motivação para trabalho & 0,14 & 0,09 & 1,41 & 0,08 \\
Instrumentalidade & Motivação para trabalho & 0,26 & 0,10 & 2,81 & 0,00 \\
Participação & Motivação para trabalho & $-0,08$ & 0,06 & 0,25 & 0,40 \\
Avaliação geral sistema de metas & Motivação para trabalho & $-0,07$ & 0,05 & 0,04 & 0,48 \\
Avaliação das recompensas & Motivação para trabalho & $-0,10$ & 0,08 & 0,70 & 0,24 \\
Valência das recompensas externas & Motivação para trabalho & $-0,12$ & 0,08 & 0,70 & 0,24 \\
Valência da missão & Motivação para trabalho & 0,39 & 0,09 & 4,32 & 0,00 \\
Autoeficácia & Avaliação geral sist. de metas & 0,06 & 0,05 & 1,03 & 0,15 \\
Dificuldade & Avaliação geral sist. de metas & 0,06 & 0,05 & 0,65 & 0,26 \\
Especificidade & Avaliação geral sist. de metas & $-0,06$ & 0,05 & 0,30 & 0,38 \\
Feedback & Avaliação geral sist. de metas & 0,33 & 0,07 & 4,44 & 0,00 \\
Importância & Avaliação geral sist. de metas & 0,21 & 0,07 & 3,04 & 0,00 \\
Participação & Avaliação geral sist. de metas & 0,28 & 0,08 & 3,33 & 0,00 \\
Equidade & Avaliação das recompensas & 0,24 & 0,10 & 2,24 & 0,01 \\
Expectativa & Avaliação das recompensas & $-0,03$ & 0,02 & 0,17 & 0,43 \\
Instrumentalidade & Avaliação das recompensas & 0,13 & 0,06 & 2,12 & 0,02 \\
Valência das recompensas externas & Avaliação das recompensas & 0,53 & 0,10 & 5,37 & 0,00 \\
& Avaliação das recompensas & 0,09 & 0,04 & 2,12 & 0,02 \\
\hline
\end{tabular}

Fonte: Dados da pesquisa.

Obs.: a) PESO: peso padronizado estimado para população; b) ERRO: erro estimado; c) T: valor t, é a razão entre o peso não padronizado pelo seu erro padrão; d) sig.: significância unicaudal do teste, exceto na relação entre valência das recompensas externas e importância, onde se mostra o teste bicaudal pelo fato de a direção ser contrária à proposta no modelo.

Em resumo, os resultados acima confirmam: 1) A avaliação geral do sistema de metas e a avaliação geral do sistema de recompensas não mostraram influência significativa sobre a motivação; 2) Os construtos que influenciam a motivação na amostra pesquisada, em ordem decrescente de representatividade, são: a valência da missão, a instrumentalidade e a autoeficácia. Esses construtos explicaram mais de 50\% da sua variação; 3) A autoeficácia foi influenciada pela especificidade das metas, que explicou mais de $26 \%$ de sua variação; 4) A especificidade foi influenciada pelo feedback recebido em relação às metas, tendo $24,6 \%$ de sua variação explicada por esse construto; 5) A importância atribuída às metas foi influenciada, em ordem decrescente de representatividade, pela valência da missão, pela avaliação geral do sistema de recompensas e pela valência das recompensas externas. Ela teve 34,6\% de sua variação explicada neste modelo. Importante observar que, neste caso, a valência das recompensas externas apresentou correlação negativa com a importância das metas, com peso de -0,19. Isso significa que a valência das recompensas externas (extrínsecas) influencia negativamente a importância das metas na amostra pesquisada.

A figura 5 mostra as relações que apresentaram significância estatística no modelo testado. 
Figura 5

Relações significativas do modelo (figura 4) confirmadas pela pesquisa

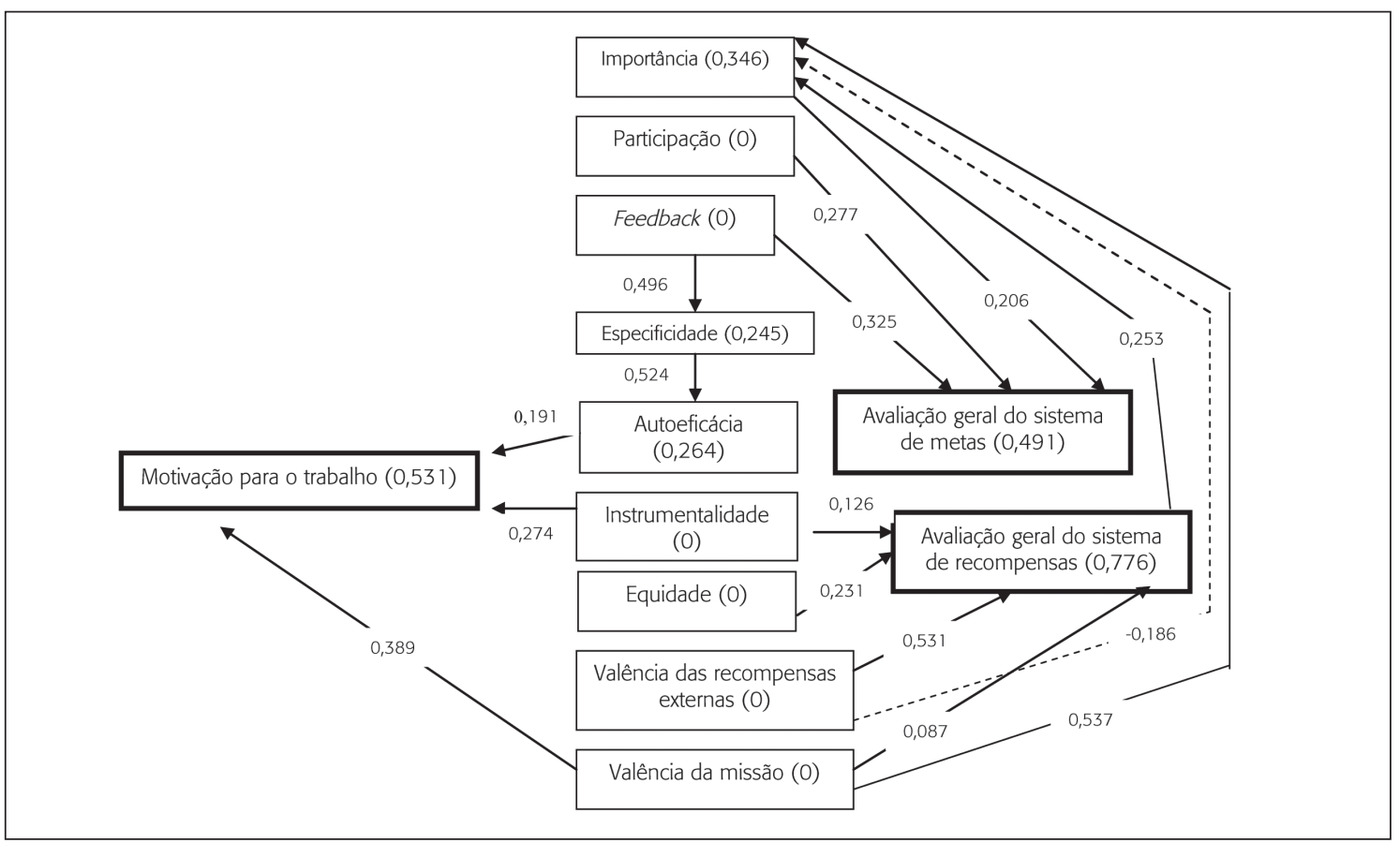

Fonte: Elaborado pelos autores com os dados da pesquisa.

\subsection{Discussão dos resultados}

Analisando os resultados referentes ao construto motivação, percebe-se que os achados reforçam algumas das questões mais importantes verificadas na literatura (Locke e Latham, 2002; Porter e Lawler III, 1968; Vroom, 1964; Wright, 2001, 2007). Três construtos mostraram possuir maior representatividade e são, portanto, os principais determinantes da motivação para o trabalho na amostra pesquisada: a autoeficácia, a valência da missão e a instrumentalidade.

A autoeficácia corresponde à sensação de competência do empregado para o desempenho das tarefas. No teste Chaid, a autoeficácia mostrou-se influenciada pela faixa etária, com valores médios percebidos mais elevados em pessoas acima de 36 anos. Isso pode ser compreensível uma vez que, em geral, as pessoas mais velhas possuem mais experiência e, portanto, sentem-se mais capacitadas para realizar as tarefas. No teste do modelo, a autoeficácia mostrou-se influenciada diretamente pela especificidade das metas e indiretamente pelo feedback em relação às metas, além de apresentar influência direta e significativa na motivação. Em outras palavras, o estudo também mostrou que a autoeficácia é maior quando os funcionários têm mais experiência, têm metas claras e específicas definidas (individuais) 
e recebem feedback em relação ao seu progresso no alcance das mesmas. Tais constatações confirmam e reforçam os resultados da literatura revisada, tanto no ambiente privado como no setor público (Locke e Latham, 2002; Wright, 2001, 2007).

A valência da missão mostrou-se influenciada pela faixa etária no teste Chaid, onde as pessoas mais velhas apresentaram médias maiores de percepção acerca desse construto. Foi verificada, também, influência significativa sobre a importância das metas, confirmando os estudos de Wright (2007). No entanto, esse construto foi o que exerceu maior influência sobre a motivação para o trabalho, dentre todos os pesquisados. Isto significa dizer que o principal motivador na amostra pesquisada é o valor intrínseco percebido pelos funcionários no próprio trabalho e na missão peculiar do serviço público, ou seja, o trabalho em si e o valor agregado à sua realização são alguns dos principais motivadores. Essa constatação também confirma e reforça a convicção de pesquisadores do comportamento humano no setor público (Chanlat, 2002; Mann, 2006; Moynihan e Pandey, 2007).

A instrumentalidade foi o segundo construto que apresentou maior influência na motivação para o trabalho. Ela corresponde à percepção de que o desempenho conduzirá a uma recompensa. Isto significa que os níveis de motivação na amostra estudada são maiores quando existe possibilidade de recebimento de recompensas. Essa constatação apenas reforça a validade da teoria da expectativa para o caso de funcionários públicos mineiros. Tais resultados corroboram com Porter e Lawler III (1968) e Vroom (1964).

O teste Chaid mostrou que quem recebe recompensas extras (além do salário fixo) tem uma percepção de instrumentalidade mais elevada do que quem não recebe. Se, por um lado, as recompensas externas influenciam a instrumentalidade e, consequentemente, a motivação, por outro, o mesmo estudo não confirma a influência direta da valência das recompensas externas sobre a motivação. Uma maneira de interpretar esses resultados é que as recompensas externas não são motivadoras por si sós. Elas são motivadoras apenas quando são vinculadas ao desempenho, ou seja, quando existe a possibilidade de recebêlas pelo alcance das metas ou de um bom desempenho. O fato de as recompensas externas combinadas com a instrumentalidade terem gerado motivação reforça os achados de Porter e Lawler III (1968) e Vroom (1964).

O estudo não confirmou a influência da importância, da dificuldade das metas, da participação na definição das metas, da expectativa e da equidade (Latham e Locke, 1979; Locke e Latham, 2002; Wright, 2001, 2007). Pode ser que a formulação do programa tenha sido feita adequadamente e/ou que esses elementos não fossem relevantes para a amostra investigada.

A valência das recompensas externas (extrínsecas) influenciou negativamente a importância das metas na amostra pesquisada. Esse resultado pode indicar que a atratividade das recompensas externas foi pequena. Também não se encontraram outros elementos que reforcem a suspeita de Deci e Ryan (2000) de que as recompensas externas podem reduzir a motivação intrínseca. Portanto, o assunto deve ser apurado em novas pesquisas.

A dificuldade das metas não confirmou nenhuma das relações apontadas na teoria. Tendo em vista que este construto é citado em vários estudos como influenciador da motivação 
(Locke e Latham, 2002; Wrigth, 2001, 2007), pode-se admitir a possibilidade de falhas no instrumento de pesquisa ou mesmo no método de análise da relação entre os construtos antes de uma conclusão definitiva sobre o assunto. Dessa forma, novos estudos com questões distintas para medir o construto e nova metodologia de análise devem ser realizados no sentido de se confirmar ou não essa relação no setor público brasileiro.

A participação na definição das metas afetou a avaliação geral do sistema de metas, mas não apresentou efeitos diretos sobre a motivação. O teste Chaid mostrou que a participação nas metas está ligada ao nível hierárquico, pois funcionários com algum nível de chefia apresentaram médias mais elevadas neste construto. A expectativa não apresentou efeitos sobre a motivação nem sobre a avaliação geral dos sistemas de recompensas na amostra estudada. No entanto, o teste Chaid mostrou que ela é maior entre os funcionários que recebem algum tipo de recompensa. Por fim, a equidade influenciou a avaliação geral das recompensas, no entanto, não confirmou relação direta significativa com a motivação.

\section{Conclusões}

De maneira geral, o estudo alcançou o objetivo de identificar como as características das metas e recompensas praticadas influenciam a motivação dos funcionários públicos no trabalho. $\mathrm{Na}$ amostra estudada, a avaliação geral do sistema de metas e a avaliação geral do sistema de recompensas não mostraram influências significativas sobre a motivação. Observou-se ainda que os construtos que influenciam a motivação em ordem decrescente de representatividade são: a valência da missão, a instrumentalidade e a autoeficácia. Esses construtos explicaram mais de $50 \%$ da sua variação. Notou-se ainda que autoeficácia foi influenciada pela especificidade das metas, que explicou mais de $26 \%$ de sua variação. A especificidade foi influenciada pelo feedback recebido em relação às metas, tendo $24,6 \%$ de sua variação explicada por esse construto. Finalmente, a importância atribuída às metas foi influenciada, em ordem decrescente de representatividade, pela valência da missão, pela avaliação geral do sistema de recompensas e pela valência das recompensas externas. Ela teve 34,6\% de sua variação explicada no modelo. Importante observar que, neste caso, a valência das recompensas externas apresentou correlação negativa com a importância das metas, com peso de $-0,19$. Isto significa que a valência das recompensas externas (extrínsecas) influencia negativamente a importância das metas na amostra pesquisada.

A sensação de competência do empregado para o desempenho das tarefas (autoeficácia) apresentou valores médios percebidos mais elevados em pessoas acima de 36 anos. Isso pode ser compreensível uma vez que, em geral, as pessoas mais velhas possuem mais experiência e, portanto, sentem-se mais capacitadas para realizar as tarefas. Já os funcionários ocupantes de cargo de chefia e aqueles que recebem algum tipo de recompensa extra, além do salário fixo, perceberam índices mais elevados em diversos fatores relacionados à motivação.

Os resultados confirmaram a influência das metas e recompensas na motivação para o trabalho, o que está de acordo com as principais teorias sobre o assunto (Locke e Latham, 
2002; Porter e Lawler III, 1968; Vroom, 1964; Wright, 2001, 2007). Isto significa que as metas e as recompensas têm efeitos válidos sobre a motivação dos funcionários do setor público mineiro. Em termos práticos, este estudo mostra que a gestão com metas e recompensas tem potencial para elevar a motivação dos servidores públicos mineiros. Ao identificar os construtos que mais influenciam a motivação, ele sinaliza o melhor caminho a ser seguido pelos gestores públicos nessa busca.

As limitações deste estudo são relacionadas, principalmente, a algumas características da amostra selecionada. No entanto, a técnica aplicada permite a generalização para os órgãos pesquisados e para aqueles com características similares. Isso significa que as conclusões aqui apresentadas podem ser entendidas como uma sinalização importante e representativa na orientação de estudos sobre o assunto no setor público brasileiro. Pode-se apontar como sugestões para futuras pesquisas sobre o tema no setor público brasileiro: 1 ) Identificar os fatores do contexto e do trabalho que mais influenciam a valência da missão, a autoeficácia e a instrumentalidade; 2) Estudar as vulnerabilidades das metas e das recompensas na motivação dos servidores públicos; 3) Estudar a influência das metas e das recompensas no desempenho dos funcionários. Apesar das limitações, fica evidenciada a importância do estudo, uma vez que seus resultados confirmam a maior parte das teorias apresentadas e sinaliza com novas contribuições. Este trabalho pode ser o ponto de partida para pesquisas mais aprofundadas, com amostras mais representativas de servidores públicos brasileiros. Diante dos resultados aqui apresentados, podem ser constituídos novos estudos, com modelos hipotéticos mais sofisticados e incorporadas novas metodologias de análise que viabilizem maior potencial de explicação das variações da motivação para o trabalho dos funcionários públicos brasileiros.

\section{Referências}

BAGOZZI, Richard P.; YI, Youjae; PHILIPS, Lynn W. Assessing construct validity in organizational research. Administrative Science Quarterly, v. 36, n. 3, p. 421-458, set. 1991.

BERGAMINI, Cecília W. Motivação nas organizações. 4. ed. São Paulo: Atlas, 1997.

BRESSER-PEREIRA, Luiz C.; SPINK, Peter K. Reforma do Estado e administração pública gerencial. Tradução de Carolina Andrade. 7. ed. Rio de Janeiro: FGV, 2006.

BUELENS, Marc; BROECK, Herman V. An analysis of differences in work motivation between public and private sector organizations. Public Administration Review, v. 67, n. 1, p. 65-74, jan. 2007.

CAMERON, Judy; BANKO, Katherine M.; PIERCE, Daniel W. Pervasive negative effects of rewards on intrinsic motivation: The myth continues. The Behavior Analyst, v. 24, n. 1, p. 1-44, 2001.

CHANLAT, Jean-François. O gerencialismo e a ética do bem comum: a questão da motivação para o trabalho nos serviços públicos. In: CONGRESO INTERNACIONAL DEL CLAD SOBRE LA REFORMA DEL ESTADO Y DE LA ADMINISTRACIÓN PÚBLICA, 7, 2002, Lisboa. Anais... Lisboa: 2002. 
CREWSON, Philip E. Public-service motivation: building empirical evidence of incidence. Journal of Public Administration Research \& Theory (Transaction), v. 7, n. 4, p. 499-518, 1997.

DECI, Edward L. Intrinsic motivation, extrinsic reinforcement, and inequity. Journal of Personality and Social Psychology, v. 22, n. 1, p. 113-120, 1972.

DECI, Edward L.; RYAN, Richard M. The "what" and "why" of goal pursuits: human needs and the self-determination of behavior. Psychological Inquiry, v. 11, n. 4, p. 227-268, 2000.

FORNELL, Class; LARCKER, David. F. Evaluating structural equation models with unobservable variables and measurement error. Journal of Marketing Research, v. 18, n. 1, p. 39-50, fev. 1981.

FREITAS, Carmen M. F. Estudo da motivação e da liderança na indústria hoteleira da RAM. Dissertação (mestrado em gestão estratégica e desenvolvimento do turismo) - Universidade de Madeira, Funchal, 2006.

FROHMAN, Mark A. Unleash urgency and action, Industry Week, v. 245, n. 20, p. 13-23, nov. 1996.

GERBING, David W.; ANDERSON, James C. An updated paradigm for scale development incorporing unidimensionality and it's assessment. Journal of Marketing Research, v. 25, p. 186-192, maio 1988.

GIL, Antônio C. Como elaborar projetos de pesquisa. 4. ed. São Paulo: Atlas, 2002.

HAENLEIN, Michael; KAPLAN, Andreas M. A beginner's guide to partial least squares (PLS) analysis. Understanding Statistics, v. 3, n. 4, p. 283-297, 2004.

HAIR JR., Joseph F. et al. Análise multivariada de dados. 5. ed. São Paulo: Bookman, 1998.

HOUSTON, David J. Public-service motivation: a multivariate test. Journal of Public Administration Research \& Theory (Transaction), v. 10, n. 4, p. 713-727, out. 2000.

HULLAND, John. Use or partial least squares (PLS) in strategic management research: a review of four recent studies. Strategic Management Journal, v. 20, n. 2, p. 195-204, 1999.

KASS, G. V. An exploratory technique for investigating large quantities of categorical data. Journal of Applied Statistics, Nova York, v. 29, n. 2, p. 119-127, fev. 1980.

KLINE, Rex B. Principles and practice of structural equation modeling. Nova York: The Guilford Press, 1998

LASHLEY, Conrad; LEE-ROSS, Darren. Organizational behavior for leisure services. Oxford: Elsevier Butterworth-Heinemann, 2003.

LATHAM, Gary P.; LOCKE, Edwin A. Goal setting: a motivational technique that works. Organizational Dynamics, Nova York, v. 8, n. 2, p. 68-80, 1979.

LAWLER III, Edward. E. Rewarding excellence: paying strategies for the new economy. San Francisco: Jossey-Brass, 2000. 
LOCKE, Edwin A. Relation of goal level to performance with a short work period and multiple goal levels. Journal of Applied Psychology, Washington, v. 67, n. 4, p. 512-515, ago. 1982.

LOCKE, Edwin A. Toward a theory of task motivation and incentives. Organizational Behavior and Human Performance, Burlington, v. 3, n. 2, p. 157-189, maio 1968.

LOCKE, Edwin A.; LATHAM, Gary P. Building a practically useful theory of goal setting and task motivation: a 35-year odyssey. American Psychological Association, v. 57, n. 9, p. 705-717, 2002.

LOCKE, Edwin A.; LATHAM, Gary P.; EREZ, Miriam. The determinants of goal commitment academy of management. The Academy of Management Review, v. 13, n. 1, p. 23-39, jan. 1988.

LUTHANS, Fred. Organizational behavior. $8^{\text {th }}$ ed. Nova York: McGraw-Hill International Edition, 1998.

MACKENZIE, Scott B. Opportunities for improving consumer research through latent variable structural equation modeling. Journal of Marketing Research, v. 28, n. 1, p. 159-166, 2001.

MALHOTRA, N. Pesquisa de marketing: uma orientação aplicada. 3. ed. Porto Alegre: Bookman, 2001.

MANN, Gregory A. A motive to serve: public service motivation in human resource management and the role of PSM in the nonprofit sector. Public Personnel Management, v. 35, n. 1, p. 33-48, 2006.

MANOLOPOULOS, D. Work motivation in the Hellenic extended public setor: an empirical investigation. The International Journal of Human Resource Management, v. 19, n. 9, p. 1738-1762, 2008.

MARUYAMA, Geoffrey M. Basics of structural equation modeling. Londres: Sage Publications, 1998.

MOWEN, John C.; MINOR, Michael S. Comportamento do consumidor. São Paulo: Prentice Hall, 2003.

MOYNIHAN, Donald P.; PANDEY, Sanjay K. The role of organizations in fostering public service motivation. Public Administration Review, v. 67, n. 1, p. 40-53, jan./fev. 2007.

NETEMEYER, Richard G.; BEARDEN, William O.; SHARMA, Subhash. Scaling procedures: Issues and Applications. s.l.: Sage, 2003.

NUNNALY, Junn C.; BERNSTEIN, Ira H. Psychometric theory. $3^{\text {rd }}$ ed. Nova York: McGrawHill, 1994.

PORTER, Lyman W.; LAWLER III, Edward E. Managerial attitudes and performance. Homewood: R. D. Irwin, 1968.

REIS NETO, Mário; MARQUES, Antônio Luiz. A satisfação dos profissionais de informática: expectativas e percepções. Revista de Negócios, Blumenau, v. 8, n. 4, p. 1-16, 2003.

RYAN, Richard M. The Oxford handbook of motivation. Oxford: Oxford University Press, 2012.

SAWREY, James; TELFORD, Charles. Psicologia educacional. Rio de Janeiro: LTC, 1976.

SCHERMERHORN JR., John R.; HUNT, James G.; OSBORN, Richard N. Fundamentos de comportamento organizacional. 2. ed. Porto Alegre: Bookman, 1999. 
SOUZA, Regina L. S. Associar o desempenho individual ao planejamento organizacional pela gestão de competências: um novo enfoque para a avaliação de desempenho na administração pública brasileira. In: CONGRESO INTERNACIONAL DEL CLAD SOBRE LA REFORMA DEL ESTADO Y DE LA ADMINISTRACIÓN PÚBLICA, 10., 2005, Santiago. Anais... Santiago: s.n., 2005.

TABACHINIK, Barbara G.; FIDELL, Linda S. Using multivariate statistics. $3^{\text {rd }}$ ed. Nova York: HarperCollins, 2001.

VIEIRA, Valter A. As tipologias, variações e características da pesquisa de marketing. Revista da FAE, Curitiba, v. 5, n. 1, p. 61-70, jan./abr. 2002.

VILHENA, Renata et al. (Org.). O choque de gestão em Minas Gerais: políticas da gestão pública para o desenvolvimento. Belo Horizonte: UFMG, 2006.

VROOM, Victor H. Work and motivation. Nova York: John Wiley \& Sons, 1964.

WRIGHT, Bradley E. Public service and motivation: does mission matter? Journal of Public Administration Review, Oxford, v. 67, n. 1, p. 54-64, jan. 2007.

WRIGHT, Bradley E. Work motivation in the public sector: an aplication of goal and social cognitive theories. Academy of Management Proceedings, Albany, p. D1-D6, 2001.

Weslei Alves Rodrigues é mestre em administração pela Universidade Fumec. E-mail: weslei2007@ gmail.com.

Mário Teixeira Reis Neto é doutor em administração pela Universidade Federal de Minas Gerais (UFMG). Professor do Programa de Mestrado e Doutorado em Administração da Universidade Fumec. E-mail: reisnetomario@gmail.com.

Cid Gonçalves Filho é doutor em administração pela Universidade Federal de Minas Gerais (UFMG). Professor do Programa de Mestrado e Doutorado em Administração da Universidade Fumec. E-mail: cid@fumec.br. 
